\title{
Research
}

\section{Effectiveness of UK provider financial incentives on quality of care:}

\author{
a systematic review
}

\begin{abstract}
Background

Provider financial incentives are being increasingly adopted to help improve standards of care while promoting efficiency.

Aim

To review the UK evidence on whether provider financial incentives are an effective way of improving the quality of health care.

\section{Design and setting}

Systematic review of UK evidence, undertaken in accordance with Preferred Reporting Items for Systematic Reviews and Meta-Analyses (PRISMA) recommendations.

\section{Method}

MEDLINE and Embase databases were searched in August 2016. Original articles that assessed the relationship between UK provider financial incentives and a quantitative measure of quality of health care were included. Studies showing improvement for all measures of quality of care were defined as 'positive', those that were 'intermediate' showed improvement in some measures, and those classified as 'negative' showed a worsening of measures. Studies showing no effect were documented as such. Quality was assessed using the Downs and Black quality checklist
\end{abstract}

\section{Results}

Of the 232 published articles identified by the systematic search, 28 were included. Of these, nine reported positive effects of incentives on quality of care, 16 reported intermediate effects, two reported no effect, and one reported a negative effect. Quality assessment scores for included articles ranged from 15 to 19 , out of a maximum of 22 points

\section{Conclusion}

The effects of UK provider financial incentives on healthcare quality are unclear. Owing to this uncertainty and their significant costs, use of them may be counterproductive to their goal of improving healthcare quality and efficiency. UK policymakers should be cautious when implementing these incentives - if used, they should be subject to careful long-term monitoring and evaluation. Further research is needed to assess whether provider financial incentives represent a cost-effective intervention to improve the quality of care delivered in the UK.

\section{Keywords}

efficiency; general practice; health policy;

hospitals; motivation; quality of health care.

\section{INTRODUCTION}

In the UK, events including inquiries into care failings at Mid Staffordshire NHS Foundation Trust and paediatric cardiac surgery at Bristol Royal Infirmary have made safety and quality of care a major priority for health professionals, politicians, and the general public. ${ }^{1,2}$ Policies aiming to improve healthcare quality frequently focus on provider financial incentives, ${ }^{2-6}$ which are being increasingly used across the NHS to promote efficiency while maintaining or improving standards of care. .,5,7-9 $^{-1}$

Provider financial incentives traditionally consist of four main approaches:

- capitation;

- fee for service;

- salary; and

- block budgets.

Since the last decade, pay-forperformance and reputational payments (public reporting or PR) are also being implemented. ${ }^{4}$ The UK Quality and Outcomes Framework (QOF), introduced in April 2004, represents the world's largest primary care pay-for-performance programme, aiming to reward general practices for delivering good-quality care.?

There is uncertainty about the effectiveness of provider financial incentives in improving the quality and safety of care. ${ }^{10,11}$ This article reviews and critically appraises the evidence on whether provider

R Mandavia, MRCS, academic clinical fellow; N Mehta, MRCS, Wellcome Trust research fellow; A Schilder, PhD, FRCS, ear, nose and throat research professor director, evidENT team, UCL Ear Institute, London. E Mossialos, MD, MSc, $\mathrm{PhD}$, professor of health policy, Centre for Health Policy, Imperial College London, London.

\section{Address for correspondence}

Rishi Mandavia, evidENT Team, UCL Ear Institute, Royal National Throat, Nose and Ear Hospital, 330 Grays Inn Road, London, WC1X 8DA, UK. financial incentives are an effective way of improving the quality of care delivered by health systems. As the international evidence has been systematically reviewed in previous work, $4,5,7,12$ this review focuses on the UK literature, aiming to specifically inform UK decision makers.

\section{METHOD}

A systematic review of the UK literature assessing the use of provider financial incentives to improve the quality of health care was performed; Preferred Reporting Items for Systematic Reviews and MetaAnalyses (PRISMA) recommendations were adhered to. ${ }^{13} \mathrm{~A}$ senior expert librarian designed and conducted a comprehensive search of the MEDLINE and Embase databases from inception until August 2016 using the Ovid portal. The search terms used were: provider; providers; physicians; hospital; financial incentives; payment; reimbursement; fees; payment system; patient safety; quality of care; quality of healthcare; quality of health care; Britain or United Kingdom or UK or England or Northern Ireland or Wales or Scotland.

Two authors, working independently, screened all titles and abstracts for eligibility; records considered potentially relevant were retrieved in full text and assessed. Reference lists of review articles were also screened to identify additional relevant articles. Any disagreements were discussed with the senior researcher and

\section{E-mail: r.mandaviađucl.ac.uk}

Submitted: 24 December 2016; Editor's response: 28 February 2017; final acceptance: 17 March 2017.

\section{British Journal of General Practice}

This is the full-length article (published online 10 Oct 2017) of an abridged version published in print. Cite this version as: Br J Gen Pract 2017; DOI: https://doi.org/10.3399/bjgp17X693149 


\section{How this fits in}

Provider financial incentives are increasingly being used in the NHS to promote efficiency while improving the quality of health care. This systematic review concludes that the effects of UK provider financial incentives on care quality are unclear - using such incentives may, in fact, be counterproductive to their desired aim of improving the quality and efficiency of health care.

resolved by consensus. Information was extracted independently by two authors and disagreements were resolved through discussion and consensus.

English-language, original articles that assessed the relationship between UK provider financial incentives and

\section{Figure 1. PRISMA flowchart of study selection process.}

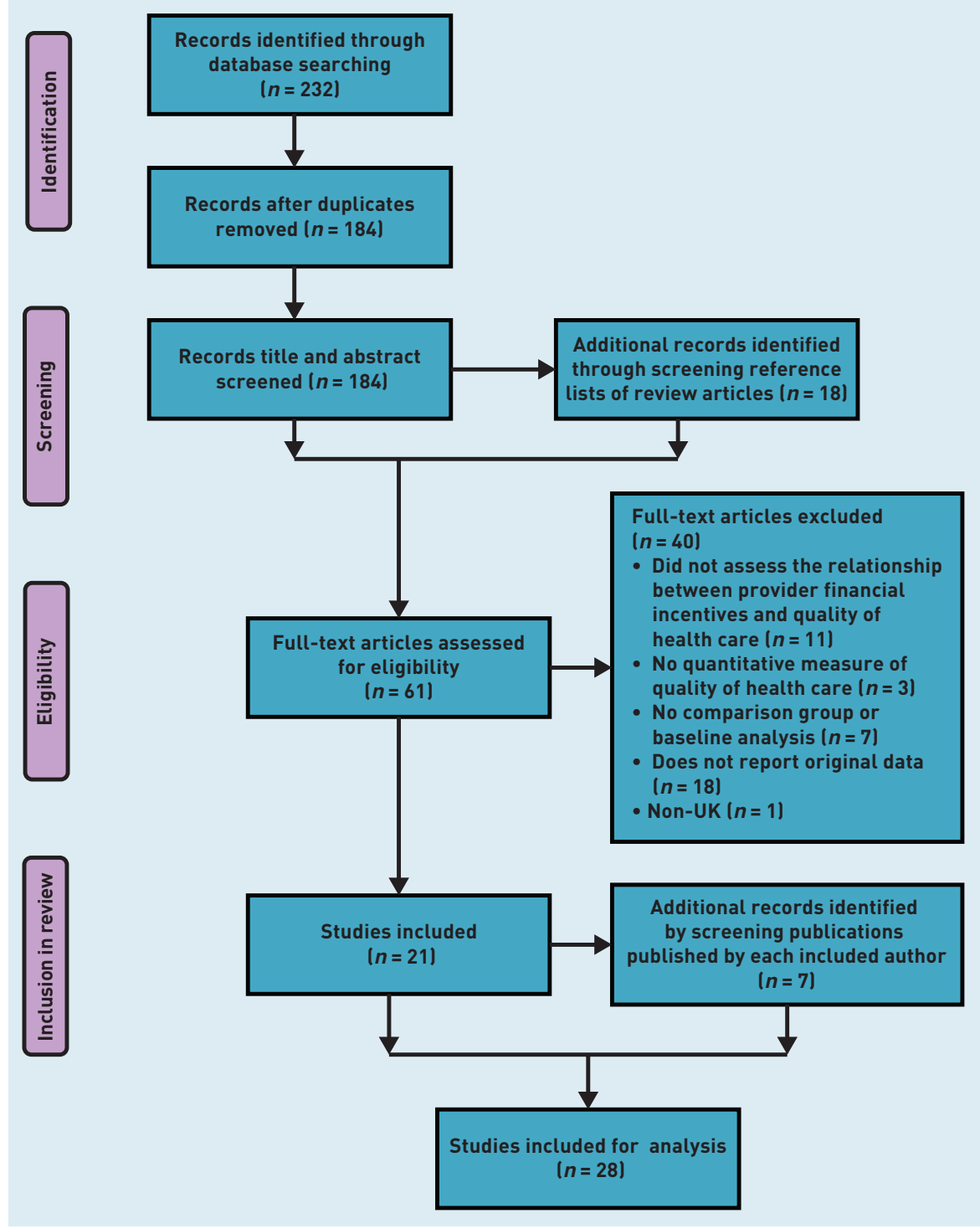

a quantitative measure of the quality of health care were included. All included articles assessed financial incentives as the independent variable, and quality of health care as the dependent variable. Articles were excluded if there was no comparison group or baseline analysis before the intervention. After identifying the articles to be included in the review, all publications by each included author were screened on 1 September 2016 to identify any other relevant articles for inclusion.

Petersen et al's $s^{5}$ method of ranking effect was used:

- positive: showed improvement for all measures of quality of care;

- intermediate: showed improvement in some measures of quality, but not all

- negative: showed a worsening of measures of quality.

Articles showing no effects were documented as such. ${ }^{5}$ The quality of included papers was assessed using the quality assessment checklist published by Downs and Black; ${ }^{14}$ certain questions (namely 15 and 23-27) of the checklist were omitted due to the nature of included evidence. Owing to the heterogeneity of including studies, meta-analysis was not conducted and results are presented descriptively.

\section{RESULTS}

The systematic search revealed 232 publications. Removing duplicates left 184 publications, of which the title and abstract were screened. Sixty-one articles were full-text assessed; 21 fulfilled the criteria for inclusion. The PRISMA flowchart can be seen in Figure 1. After screening all other publications by each included author, seven additional papers were included, resulting in 28 articles for analysis. Study designs included differencein-differences regression analyses, regression discontinuity design, synthetic control method, retrospective analyses, probit modelling, longitudinal studies, cohort studies, cross-sectional studies, and interrupted time series analyses.

Appendix 1 summarises the 28 included studies along with their quality scores. One study, assessing the effects of Payment by Results on acute care hospitals, showed an intermediate effect on quality of care. ${ }^{15}$ Five articles examined the impact of pay for performance in hospitals - two studies showed a positive effect, 16,17 two an intermediate effect, ${ }^{18,19}$ and one a negative effect. ${ }^{20}$ Twenty-one articles assessed the 
impact of the pay-for-performance QOF scheme in the primary care setting, with seven studies showing a positive effect, 13,21-26 13 showing an intermediate effect, 11,27-38 and one showing no effect. ${ }^{39}$ One article reporting on the effects of the QOF on the UK population level showed no effect. ${ }^{40}$

In total, nine articles reported positive effects of financial incentives, 16 reported intermediate effects, two reported no effect, and one reported a negative effect.

\section{Studies reporting positive effects}

Allen et al ${ }^{17}$ found that the introduction of a best-practice tariff in English hospitals was associated with reductions in postoperative length of stay and a lower proportion of laparoscopic cholecystectomies being converted to open procedures. The impact of the Advancing Quality pay-for-performance programme on hospital mortality was assessed by Sutton et al, ${ }^{16}$ who found significant reductions in mortality during the 18-month study period. An earlier study by Sutton et al ${ }^{21}$ assessed the quality of care following implementation of the QOF scheme; it showed that annual recording rates of blood pressure, smoking status, cholesterol, body mass index, and alcohol consumption had increased by $19.9 \%$. Five studies $22-25,41$ investigating clinical outcomes of patients with diabetes after implementation of the QOF found significant improvements in glycated haemoglobin $(\mathrm{HbA1})$ levels, total cholesterol, and blood pressure levels. Fichera et $a^{26}$ identified that the introduction of the QOF was followed by improved lifestyle behaviours for individuals with targeted health conditions.

\section{Studies reporting intermediate effects}

Farrar et $a l^{15}$ found that the introduction of Payment by Results in acute care hospitals was associated with a significant reduction in in-hospital mortality, but there was no significant change in 30-day post-surgical mortality or emergency re-admission after being treated for hip fracture. Studies by Kristensen et al ${ }^{18}$ and McDonald et al ${ }^{19}$ reported that, although the Advancing Quality pay-for-performance programme in English hospitals led to initial reductions in hospital mortality, these reductions were greater in non-participating hospitals ${ }^{16}$ and, by the end of the follow-up period, were not maintained. ${ }^{18,19}$

Vamos et $a^{33}$ and Alshamsan et $a^{34}$ examined the impact of the QOF on the achievement of national targets for blood pressure, HbA1c levels, and cholesterol. Vamos et $a^{33}$ showed that, after the QOF had been implemented, there were significant improvements for cholesterol and blood pressure, but not for $\mathrm{HbA1c}$ level.
Alshamsan ${ }^{34}$ found that:

- HbA1c levels significantly worsened compared with the baseline;

- cholesterol levels initially reduced in white and black patients, but not in South Asian patients; and

- 3 years later, cholesterol levels significantly increased in white patients.

The QOF was associated with initial improvements in blood pressure but these were not sustained in the post-QOF implementation period. Similar findings were obtained by Lee et al. ${ }^{36} \mathrm{~A}$ local version of the QOF, assessed by Pape et al, ${ }^{35}$ led to higher target achievements for hypertension, heart disease, and stroke; however, this was driven by higher rates of exception reporting and there were no improvements in mean blood pressure, cholesterol, or $\mathrm{HbA1c}$ levels.

The impact of the QOF scheme on diabetes management was assessed by Millett et al, ${ }^{27}$ who found that, although there were improvements for patients with diabetes who had comorbidities, there was a negative impact on those with diabetes and no comorbidities. Longitudinal studies by Campbell et al ${ }^{11,28}$ showed initial improvements in quality of care for patients with asthma and diabetes, but not for those with coronary heart disease; the rate of improvement slowed for all conditions. Continuity of care was found to reduce immediately after the implementation of the QOF."1

Calvert et $a l_{1}^{29}$ investigating the impact of the QOF on diabetes management, showed that existing improvement rates in glycaemic control, cholesterol levels, and blood pressure reduced after implementation of the QOF. There was no improvement in the number of patients with type 2 diabetes and $\mathrm{HbA} 1 \mathrm{c}$ levels of $>10 \%$; in addition, the QOF may have increased the number of patients with type 2 diabetes and $\mathrm{HbA} 1 \mathrm{c}$ levels of $\leq 7.5 \%$.

Millett et a ${ }^{30}$ found that the introduction of the QOF was followed by reductions in mean blood pressure for white, black, and South Asian groups. However, HbA1c levels were only significantly reduced for white groups, potentially increasing ethnic inequity. A similar study by Hamilton et a/ ${ }^{38}$ found reduced disparities in diabetes outcomes between males and females post-QOF, but there was a widening of age group disparities.

Two studies ${ }^{31,32}$ examined the achievement rates of quality indicators after the QOF scheme was introduced. Although there 
were significant increases in the rate of improvement of incentivised quality indicators, for non-incentivised indicators there was no significant effect in the first year and, by 2007, achievement rates were significantly lower than expected. ${ }^{31,32}$ The impact of a local QOF initiative on smoking cessation was assessed by Hamilton et al, ${ }_{1}^{37}$ who found increased recording of smoking status and smoking cessation advice. However, age, social, and ethnic inequalities were associated with these findings.

\section{Studies reporting no effect}

Serumaga et al $^{39}$ assessed the effect of the QOF on patients with hypertension and found:

- no significant change in blood-pressure monitoring, control, or treatment intensity; and

- no effects on hypertension-related adverse outcome or all-cause mortality.

Similarly Ryan et al ${ }^{40}$ found no significant associations between the introduction of the QOF and changes in population mortality.

\section{Studies reporting negative effects}

Kreif et a ${ }^{20}$ re-analysed data from the study by Sutton et $a l^{16}$ and found that the Advancing Quality pay-for-performance programme was associated with statistically significant increases in mortality for non-incentivised conditions, with no significant reductions in incentivised conditions.

\section{Quality of included studies}

Quality scores for the included studies ranged from 15 to 19 , out of a maximum of 22 points. Points often missed on the quality checklist were for failing to:

- describe characteristics of included patients;

- describe distributions of potential confounders;

- report adverse events;

- describe characteristics of patients lost to follow-up; and

- take into account patient loss to follow-up. Other missed criteria included:

- providing estimates of random variability;

- reporting actual probability values for the main outcomes;

- adjusting for different lengths of patient follow-up; and

- recruitment of patients from the same population.

\section{DISCUSSION}

Summary

Twenty-eight eligible UK studies assessed the use of provider financial incentives to improve the quality of health care. Six studies reported on the effects in hospitals, ${ }^{15-20} 21$ focused on the general practice setting, 11,13, 21-39 and one article reported at the UK population level. ${ }^{40}$ Nine articles reported positive effects of incentives on quality of care, 16,17,21-26,41 16 reported intermediate effects, ${ }^{11,15,18,19,27-38}$ two reported no effect, ${ }^{39,40}$ and one reported a negative effect. ${ }^{20}$ Quality assessment scores for the included articles ranged from 15 to 19 , out of a maximum of 22 points.

There is evidence of adverse effects including worsening of quality outcomes, ${ }^{27,34}$ reduced continuity of care, ${ }^{11}$ increased inequity among ethnic groups and age groups, ${ }^{30,34,36-38}$ increased exception reporting, ${ }^{35}$ and non-incentivised conditions having higher mortality levels and receiving poorer quality of care. ${ }^{20,31}$

The different study designs employed by the articles in the review do not appear to lean towards a higher-quality score or effect size. Similarly, articles with the highestquality scores do not appear to lean towards a positive, intermediate, or negative ranking effect.

\section{Strengths and limitations}

This systematic review may be affected by publication bias, as healthcare decision makers may not wish to publish studies showing negative effects of financial incentives. The authors acknowledge that, by only including UK evidence, potentially informative international studies were excluded. However, this study is particularly relevant to UK policymakers, being the only systematic review evaluating the effectiveness of UK provider financial incentives on improving the quality of care.

All included studies had a baseline or comparison group, and quality assessment of included articles was conducted using a validated and transparent quality checklist. Quality assessment scores suggest that, within the constraints of this research area, most of the included articles were of high quality. Owing to the nature of research into financial incentives, it is very difficult to perform randomised controlled trials, adjust for confounding, report on all adverse events, and account for patients lost to follow-up.

The generalisability of findings is limited, with the majority of studies focusing on the QOF incentive as opposed to other types of provider financial incentives. The impact of the QOF is particularly difficult to assess as 
the incentive was implemented nationwide, leaving no clear control group. Moreover, the quality of care was already improving before the QOF was implemented and it is unclear whether improvements exceeded previous trends after the incentive - especially considering that quality outcomes have been measured for fewer than 3 years postimplementation. ${ }^{11,28,29,41}$ The amount of UK evidence available that assesses the effects of Payment by Results is limited - only one study was identified. ${ }^{15}$

\section{Comparison with existing literature}

International research also suggests that the effects of provider financial incentives on healthcare quality are unclear and that the evidence base is unable to support widespread implementation into health policy.,42-45 There have been no randomised control trials evaluating provider financial incentives, and the majority of studies have no control groups and lack generalisability. 10,42 Studies with control groups have mixed results, and relatively few significant improvements are reported. 7.10,42,46

A number of adverse effects to provider financial incentives have been reported internationally. These include reduced clinician job satisfaction, ${ }^{47}$ declining continuity of care, ${ }^{11}$ diverting focus from quality of care to quality of record keeping, ${ }^{42}$ increased gaming, ${ }^{48}$ and exception reporting. ${ }^{42}$ Mendelson et $a l_{1}{ }_{1}^{45}$ in their recent systematic review, concluded that there was no clear evidence to suggest that pay-for-performance programmes improve patient outcomes in any healthcare setting. Markovitz and Ryan ${ }^{44}$ systematically assessed whether these apparently disappointing results of provider incentives are masked by heterogeneity of patient and catchment factors, organisational and institutional capabilities, and programme characteristics - they found that accounting for this heterogeneity does not sufficiently alter the conclusion that provider financial incentives have largely failed to improve healthcare quality.

\section{Implications for research}

These findings suggest that the effects of UK provider financial incentives on healthcare quality are unclear. Included studies lack consensus: the majority show an improvement in some quality measures, but not all, and demonstrate that, although incentives may initially improve quality, these improvements can plateau or even decline. 11,18,19,32-34,41 This uncertainty is also apparent when considering the effects of different types of financial incentive on quality of care.

Despite uncertainly about their effectiveness, provider financial incentives receive widespread political attention and are increasingly being implemented. ${ }^{42}$ UK policymakers should be cautious - if implemented, these incentives should be subject to careful long-term monitoring and evaluation so that the origins of shortcomings can be understood and acted on.

Another factor to bear in mind is that provider financial incentives are expensive; the total annual expenditure for the QOF alone is approximately $€ 1$ billion. ${ }^{10}$ Given the unclear effects on healthcare quality, these significant costs do not appear to be justified and, added to that, the use of provider financial incentives may be counterproductive to the intended aim of improving healthcare efficiency. ${ }^{10}$ Further research is needed to assess whether UK provider financial incentives do, or do not, represent a cost-effective intervention to improve the quality of care delivered.

\section{Funding}

This study received no funding.

\section{Ethical approval}

Ethical approval was not required.

\section{Provenance}

Freely submitted; externally peer reviewed

\section{Competing interests}

The authors have declared no competing interests.

\section{Discuss this article}

Contribute and read comments about this article: bjgp.org/letters 


\section{REFERENCES}

1. Jarman B. Quality of care and patient safety in the UK: the way forward after Mid Staffordshire. Lancet 2013; 382(9892): 573-575.

2. Marshall L, Charlesworth A, Hurst J. The NHS payment system: evolving policy and emerging evidence. London: Nuffield Trust, 2014. https://www. nuffieldtrust.org.uk/research/the-nhs-payment-system-evolving-policy-andemerging-evidence laccessed 7 Jun 2017)

3. Tsai TC, Jha AK, Gawande AA, et al. Hospital board and management practices are strongly related to hospital performance on clinical quality metrics. Health Aff (Millwood) 2015; 34(8): 1304-1311.

4. Roland M, Dudley RA. How financial and reputational incentives can be used to improve medical care. Health Serv Res 2015; 50(Suppl 2): 2090-2115.

5. Petersen LA, Woodard LD, Urech T, et al. Does pay-for-performance improve the quality of health care? Ann Intern Med 2006; 145(4): 265-272

6. Institute of Medicine. Crossing the quality chasm: a new health system for the 21st century. Washington, DC: National Academies Press, 2001

7. Christianson J, Leatherman S, Sutherland K. Financial incentives, healthcare providers and quality improvements. London: Health Foundation, 2007.

8. Gallagher N, Cardwell C, Hughes C, O'Reilly D. Increase in the pharmacological management of type 2 diabetes with pay-for-performance in primary care in the UK. Diabet Med 2015; 32(1): 62-68.

9. Scott A, Sivey P, Ait Ouakrim D, et al. The effect of financial incentives on the quality of health care provided by primary care physicians. Cochrane Database Syst Rev 2011; 9: CD008451.

10. Maynard A, Bloor K. Will financial incentives and penalties improve hospital care? BMJ 2010; 340: c88.

11. Campbell SM, Reeves D, Kontopantelis E, et al. Effects of pay for performance on the quality of primary care in England. N Engl J Med 2009; 361(4): 368378

12. Dudley RA, Miller RH, Korenbrot TY, Luft HS. The impact of financial incentives on quality of health care. Milbank Q 1998; 76(4): 649-686, 511.

13. Moher D, Altman DG, Liberati A, Tetzlaff J. PRISMA statement. Epidemiology 2011; 22(1): 128 .

14. Downs SH, Black N. The feasibility of creating a checklist for the assessment of the methodological quality both of randomised and non-randomised studies of health care interventions. J Epidemiol Community Health 1998 52(6): 377-384

15. Farrar S, Yi D, Sutton M, et al. Has payment by results affected the way that English hospitals provide care? Difference-in-differences analysis. BMJ 2009 339: b3047.

16. Sutton M, Nikolova S, Boaden R, et al. Reduced mortality with hospital pay for performance in England. N Engl J Med 2012; 367(19): 1821-1828.

17. Allen T, Fichera E, Sutton M. Can payers use prices to improve quality? Evidence from English hospitals. Health Econ 2016; 25(1): 56-70.

18. Kristensen SR, Meacock R, Turner AJ, et al. Long-term effect of hospital pay for performance on mortality in England. N Engl J Med 2014; 371(6): 540-548.

19. McDonald R, Boaden R, Roland M, et al. A qualitative and quantitative evaluation of the Advancing Quality pay-for-performance programme in the NHS North West. Health Services and Delivery Research 2015; 3: 23.

20. Kreif N, Grieve R, Hangartner D, et al. Examination of the synthetic control method for evaluating health policies with multiple treated units. Health Econ 2016; 25(12): 1514-1528

21. Sutton M, Elder R, Guthrie B, Watt G. Record rewards: the effects of targeted quality incentives on the recording of risk factors by primary care providers. Health Econ 2010; 19(1): 1-13.

22. Gulliford MC, Ashworth M, Robotham D, Mohiddin A. Achievement of metabolic targets for diabetes by English primary care practices under a new system of incentives. Diabet Med 2007; 24(5): 505-511.

23. Millett C, Gray J, Saxena S, et al. Ethnic disparities in diabetes management and pay-for-performance in the UK: the Wandsworth Prospective Diabetes Study. PLoS Med 2007; 4(6): e191

24. Tahrani AA, McCarthy M, Godson J, et al. Diabetes care and the new GMS contract: the evidence for a whole county. Br J Gen Pract 2007; 57(539): 483-485.

25. Tahrani AA, McCarthy M, Godson J, et al. Impact of practice size on delivery of diabetes care before and after the Quality and Outcomes Framework implementation. Br J Gen Pract 2008; DOI: https://doi.org/10.3399/ bjgp08X319729.
26. Fichera E, Gray E, Sutton M. How do individuals' health behaviours respond to an increase in the supply of health care? Evidence from a natural experiment. Soc Sci Med 2016; 159: 170-179.

27. Millett $\mathrm{C}$, Bottle $\mathrm{A}, \mathrm{Ng} \mathrm{A}$, et al. Pay for performance and the quality of diabetes management in individuals with and without co-morbid medical conditions. $J$ R Soc Med 2009; 102(9): 369-377.

28. Campbell S, Reeves D, Kontopantelis E, et al. Quality of primary care in England with the introduction of pay for performance. N Engl J Med 2007; 357(2): 181-190.

29. Calvert M, Shankar A, McManus RJ, et al. Effect of the quality and outcomes framework on diabetes care in the United Kingdom: retrospective cohort study. BMJ 2009; 338: b1870.

30. Millett C, Netuveli G. Saxena S, Majeed A. Impact of pay for performance on ethnic disparities in intermediate outcomes for diabetes: a longitudinal study. Diabetes Care 2009; 32(3): 404-409

31. Steel N, Maisey S, Clark A, et al. Quality of clinical primary care and targeted incentive payments: an observational study. Br J Gen Pract 2007; 57(539): 449-454.

32. Doran T, Kontopantelis E, Valderas JM, et al. Effect of financial incentives on incentivised and non-incentivised clinical activities: longitudinal analysis of data from the UK Quality and Outcomes Framework. BMJ 2011; 342: d3590.

33. Vamos EP, Pape UJ, Bottle A, et al. Association of practice size and pay-forperformance incentives with the quality of diabetes management in primary care. CMAJ 2011; 183(12): E809-E816.

34. Alshamsan R, Lee JT, Majeed A, et al. Effect of a UK pay-for-performance program on ethnic disparities in diabetes outcomes: interrupted time series analysis. Ann Fam Med 2012; 10(3): 228-234.

35. Pape UJ, Huckvale K Car J, et al. Impact of 'stretch' targets for cardiovascular disease management within a local pay-for-performance programme. PLoS One 2015; 10(3): e0119185.

36. Lee JT, Netuveli G, Majeed A, Millett C. The effects of pay for performance on disparities in stroke, hypertension, and coronary heart disease management: interrupted time series study. PLoS One 2011; 6(12): e27236.

37. Hamilton FL, Laverty AA, Huckvale $K$, et al. Financial incentives and inequalities in smoking cessation interventions in primary care: before-andafter study. Nicotine Tob Res 2016; 18(3): 341-350.

38. Hamilton FL, Bottle A, Vamos EP, et al. Impact of a pay-for-performance incentive scheme on age, sex, and socioeconomic disparities in diabetes management in UK primary care. J Ambul Care Manage 2010; 33(4): 336349

39. Serumaga B, Ross-Degnan D, Avery AJ, et al. Effect of pay for performance on the management and outcomes of hypertension in the United Kingdom: interrupted time series study. BMJ 2011; 342: d108.

40. Ryan AM, Krinsky S, Kontopantelis E, Doran T. Long-term evidence for the effect of pay-for-performance in primary care on mortality in the UK: a population study. Lancet 2016; 388(10041): 268-274.

41. Kontopantelis E, Reeves D, Valderas JM, et al. Recorded quality of primary care for patients with diabetes in England before and after the introduction of a financial incentive scheme: a longitudinal observational study. BMJ Qual Saf 2013; 22(1): 53-64.

42. Houle SK, McAlister FA, Jackevicius CA, et al. Does performance-based remuneration for individual health care practitioners affect patient care? A systematic review. Ann Intern Med 2012; 157(12): 889-899.

43. Flodgren G, Eccles MP. Shepperd S, et al. An overview of reviews evaluating the effectiveness of financial incentives in changing healthcare professional behaviours and patient outcomes. Cochrane Database Syst Rev; 2011; (7): CD009255

44. Markovitz AA, Ryan AM. Pay-for-performance: disappointing results or masked heterogeneity? Med Care Res Rev 2016; Jan 7. pii: 1077558715619282. [Epub ahead of print].

45. Mendelson A, Kondo K, Damberg C, et al. The effects of pay-for-performance programs on health, health care use, and processes of care: a systematic review. Ann Int Med 2017; 166(5): 341-353.

46. Lindenauer PK, Remus D, Roman S, et al. Public reporting and pay for performance in hospital quality improvement. N Engl J Med 2007; 356(5): 486-496

47. Maisey S, Steel N, Marsh R, et al. Effects of payment for performance in primary care: qualitative interview study. J Health Serv Res Policy 2008; 13(3): 133-139

48. Hamblin R. Regulation, measurements and incentives. The experience in the US and UK: does context matter? J R Soc Promot Health 2008; 128(6): 291-298. 

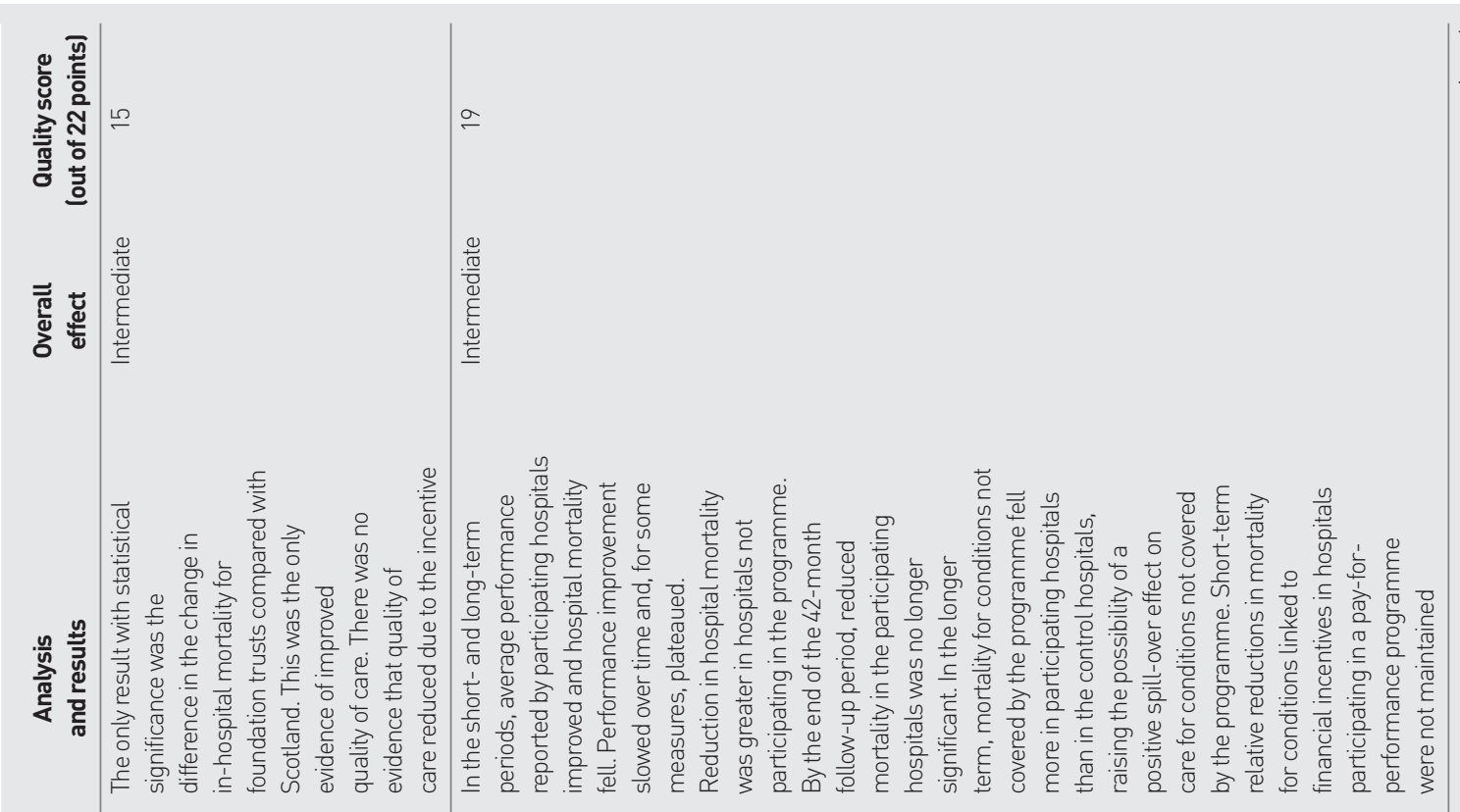

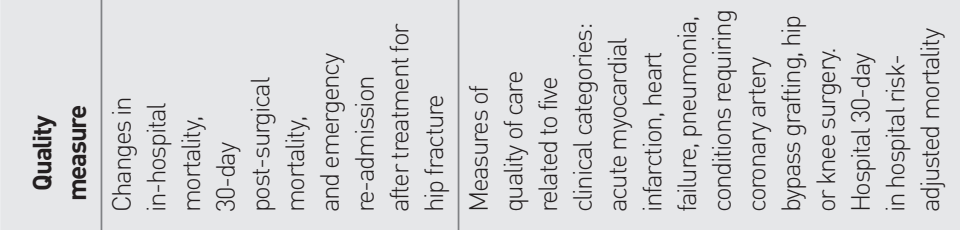

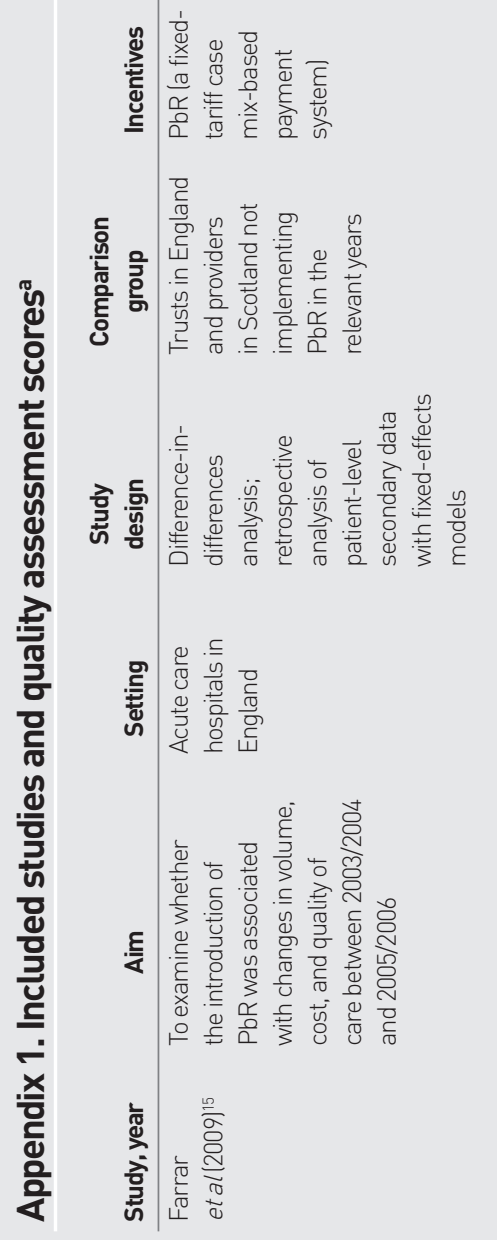

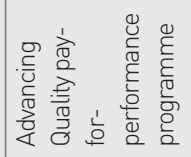

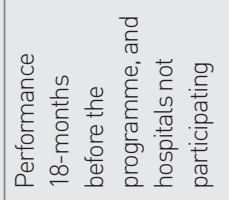

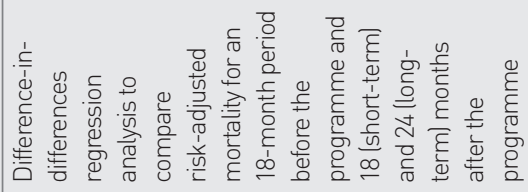

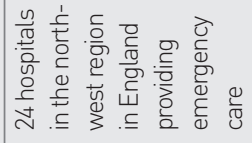

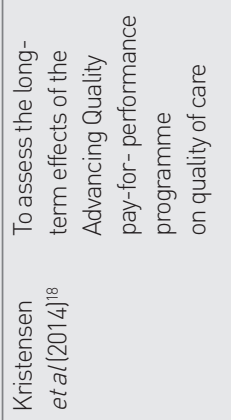




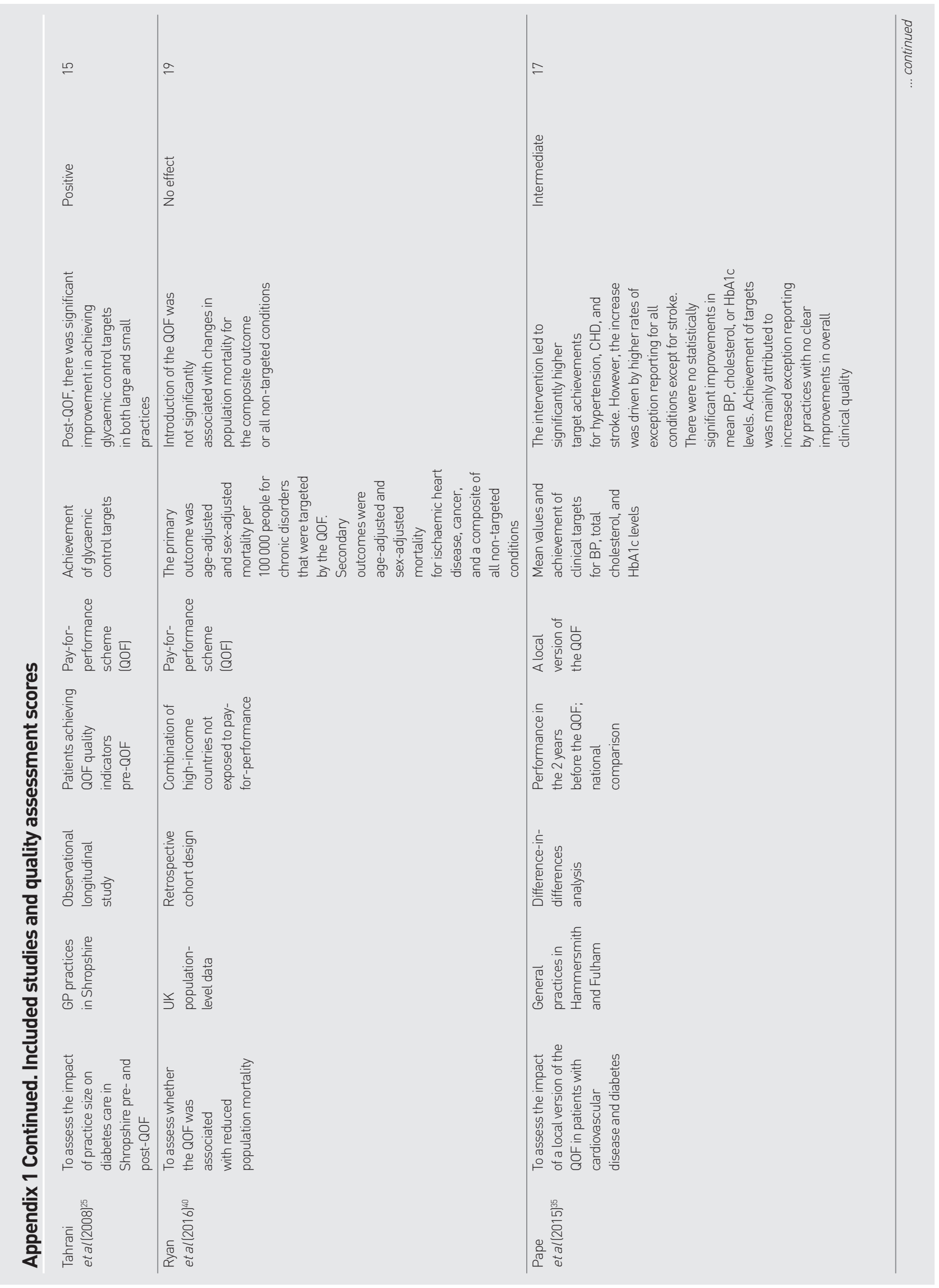




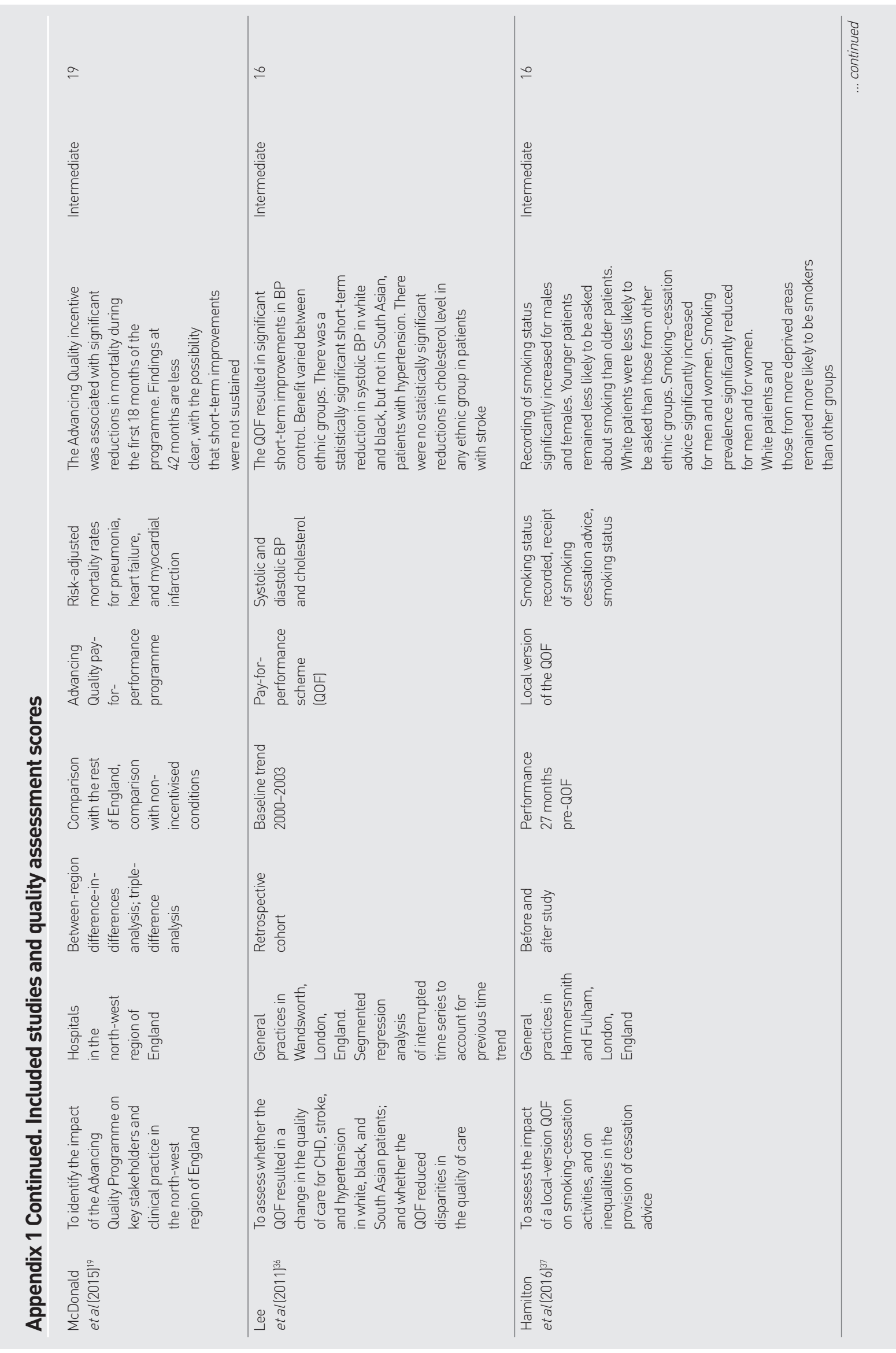




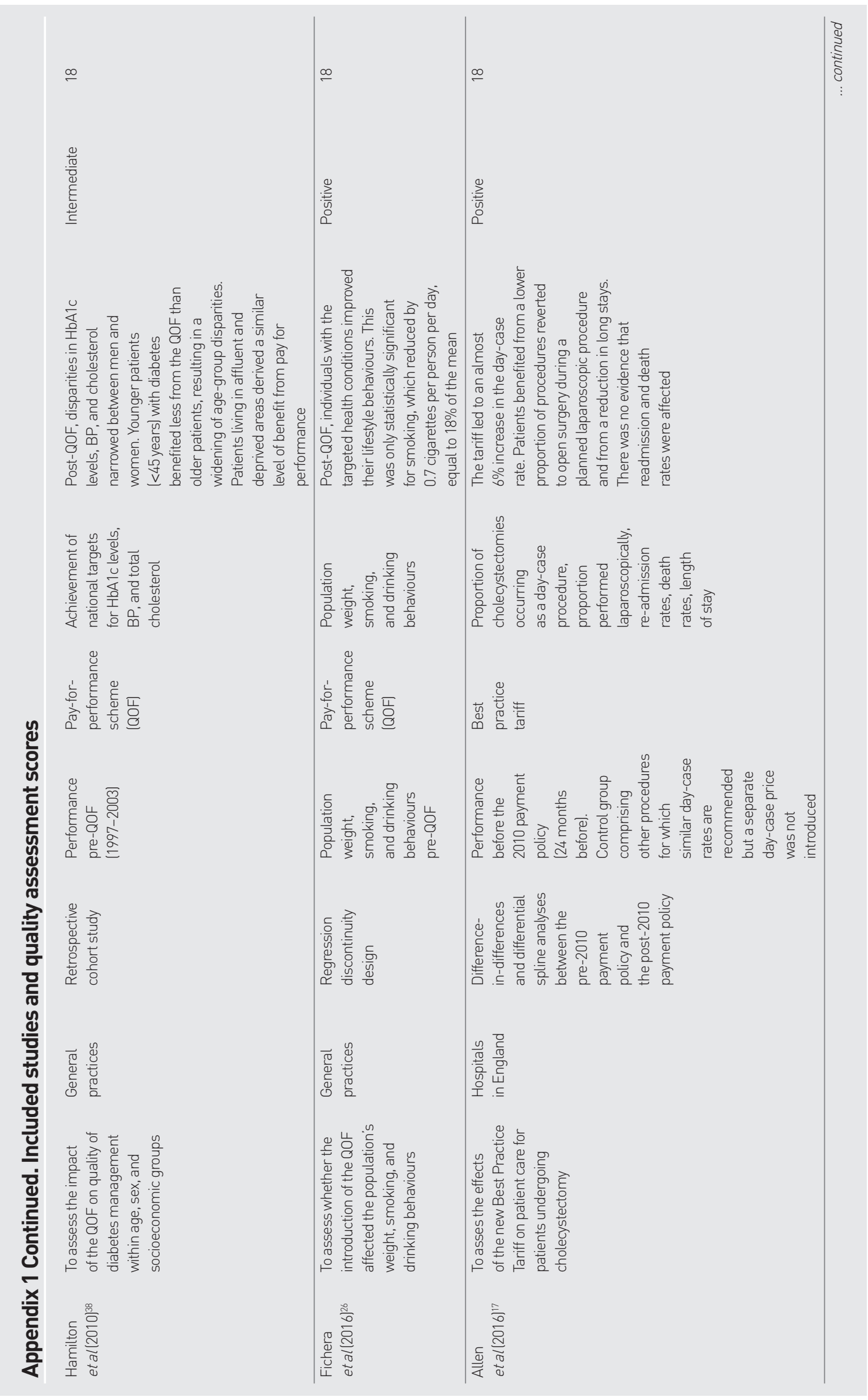




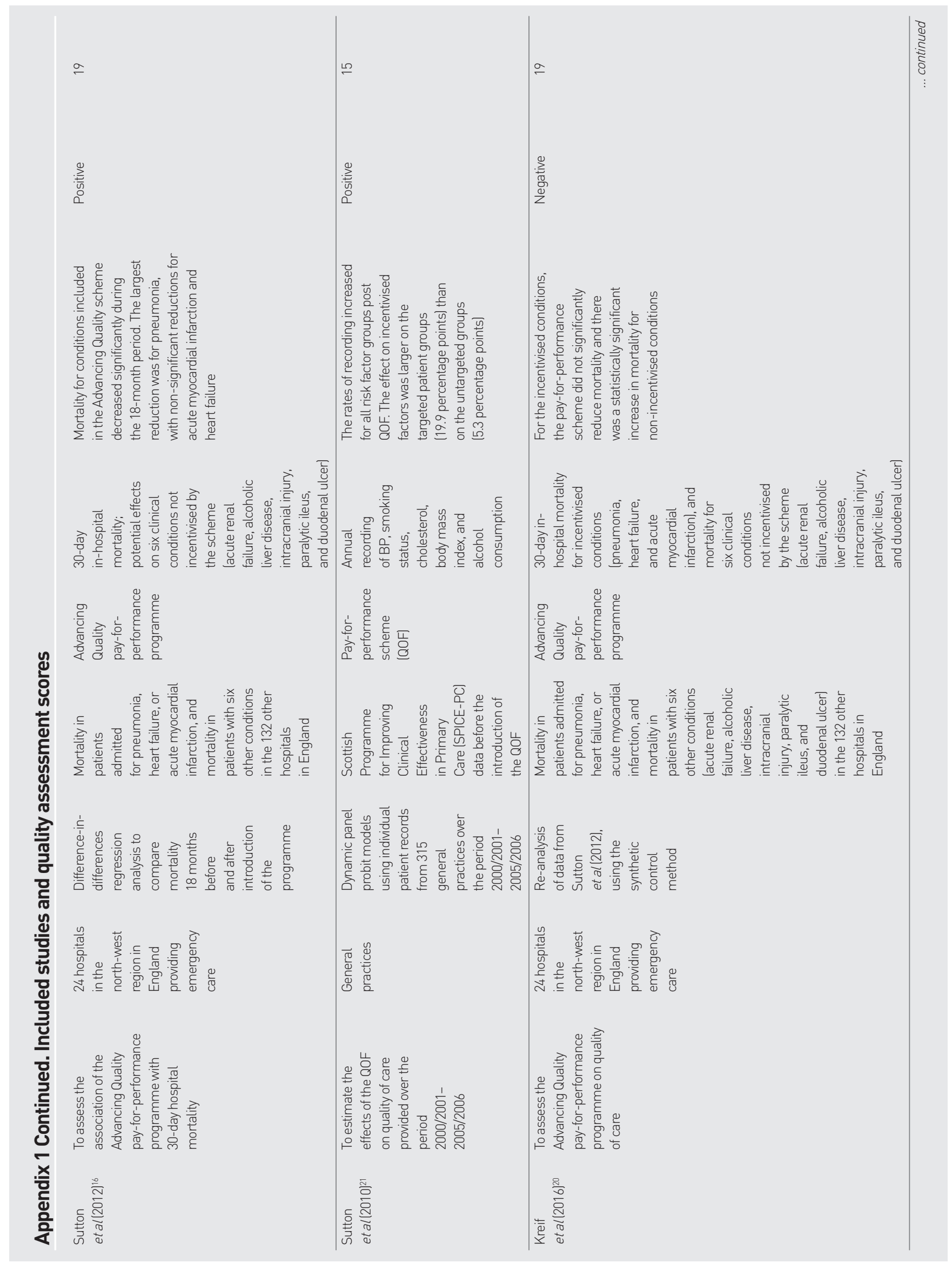




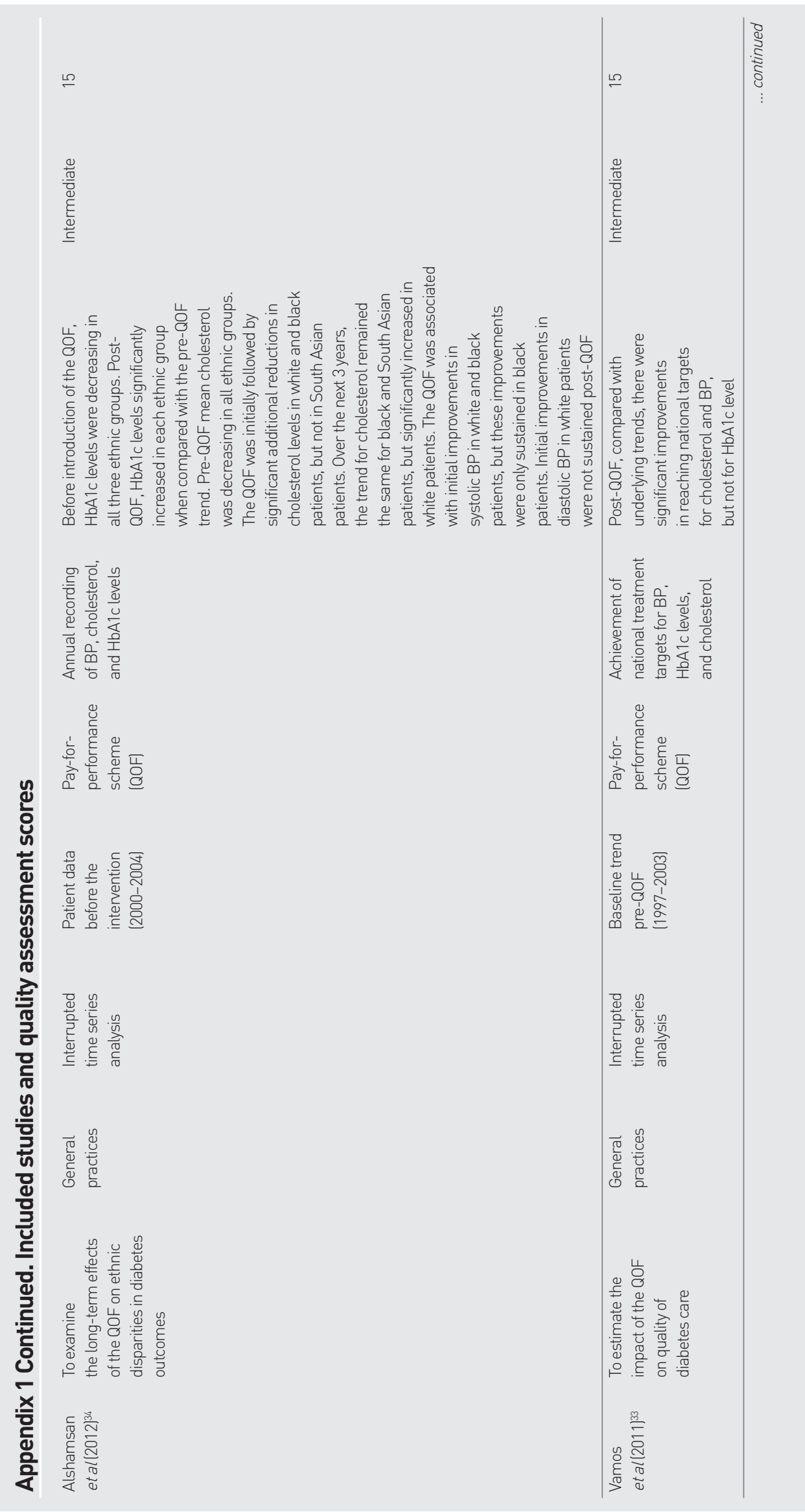




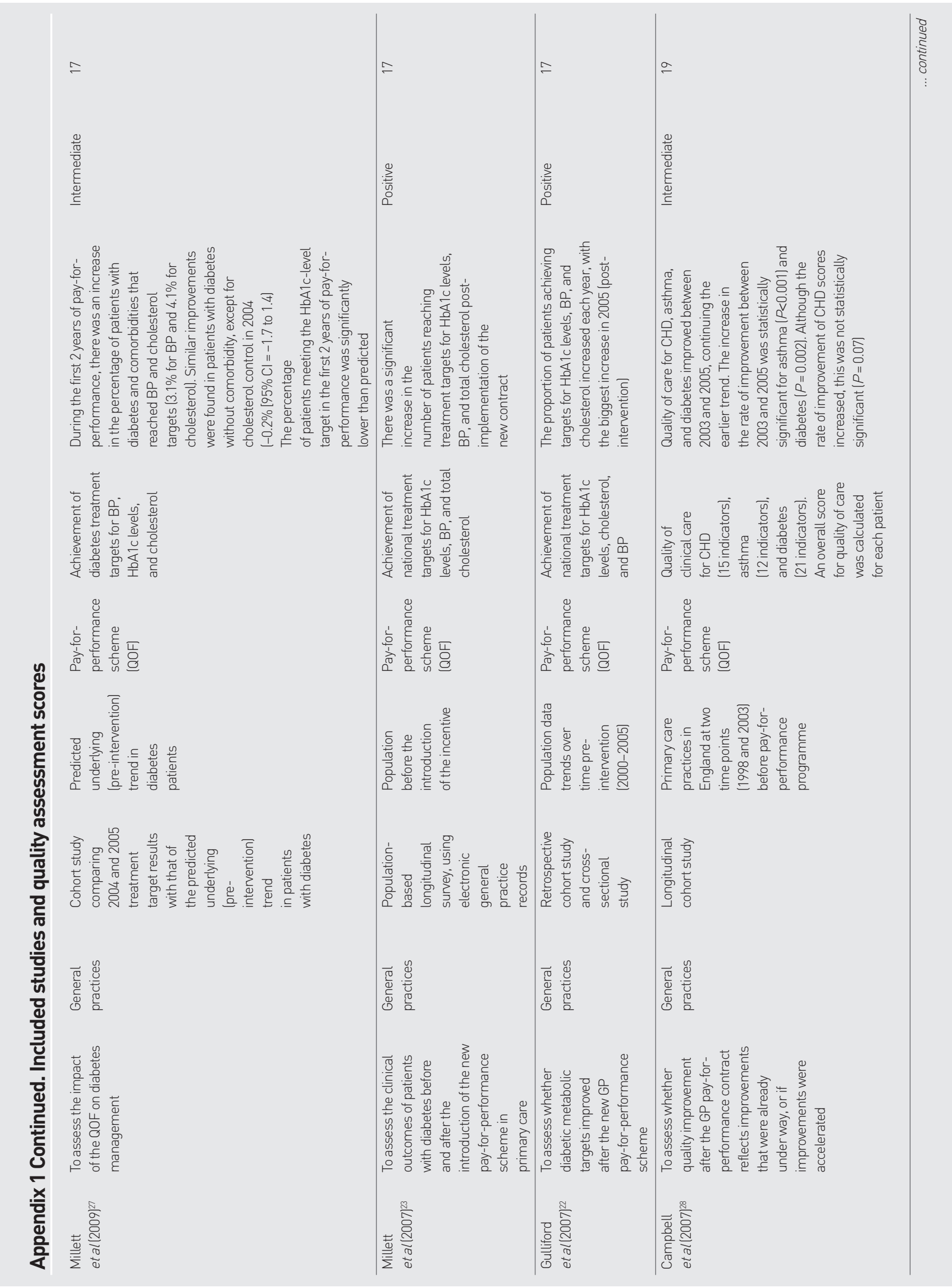




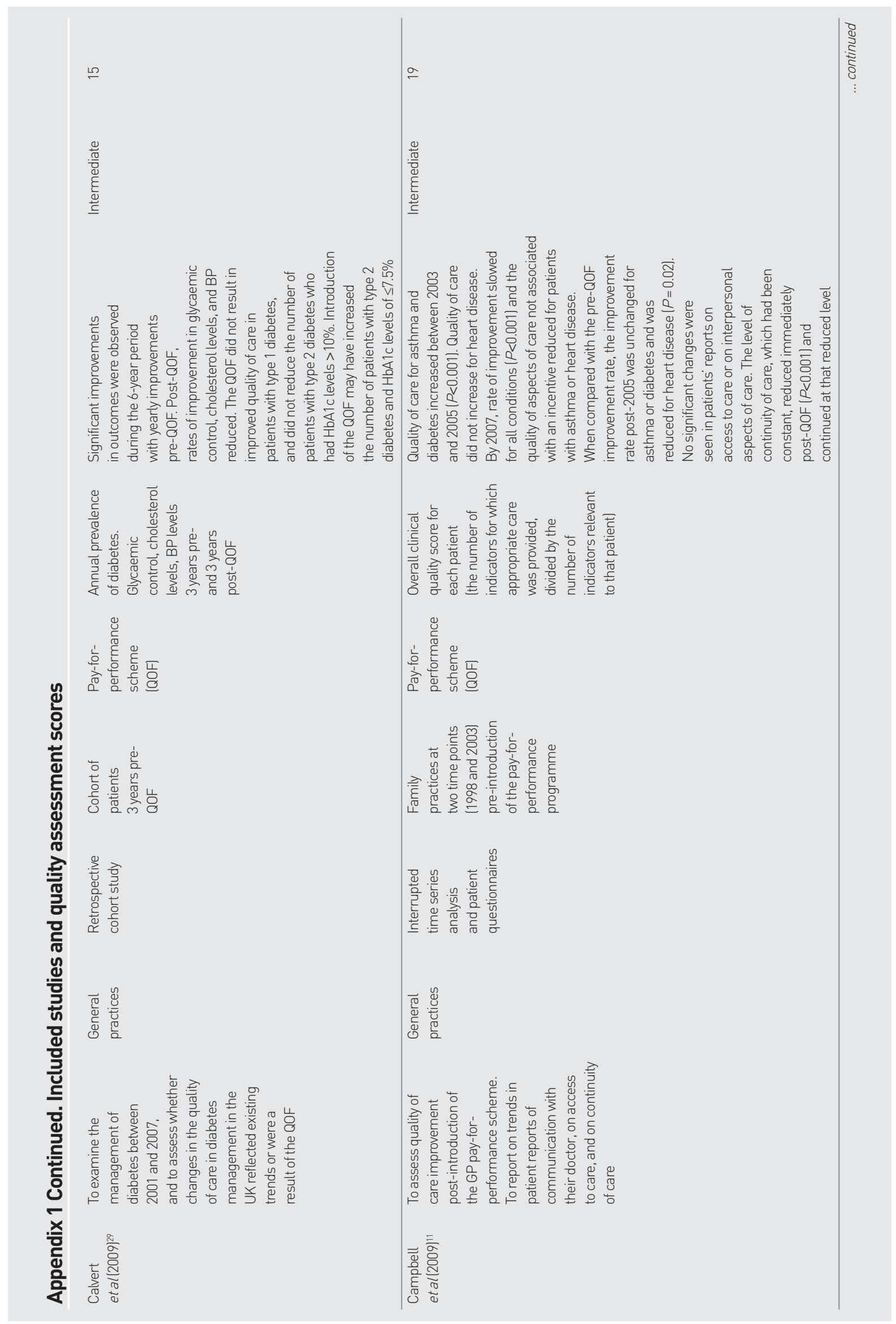




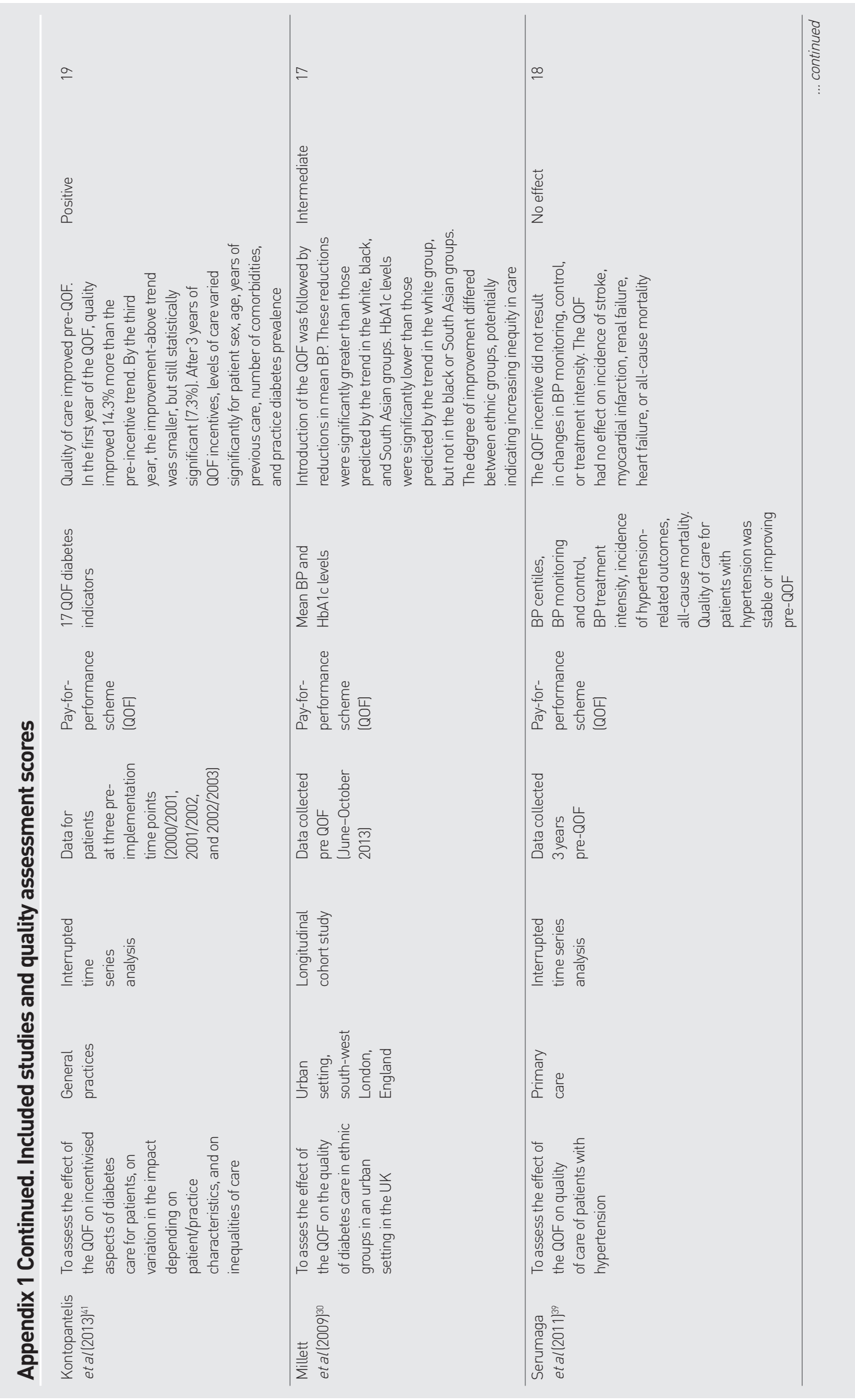




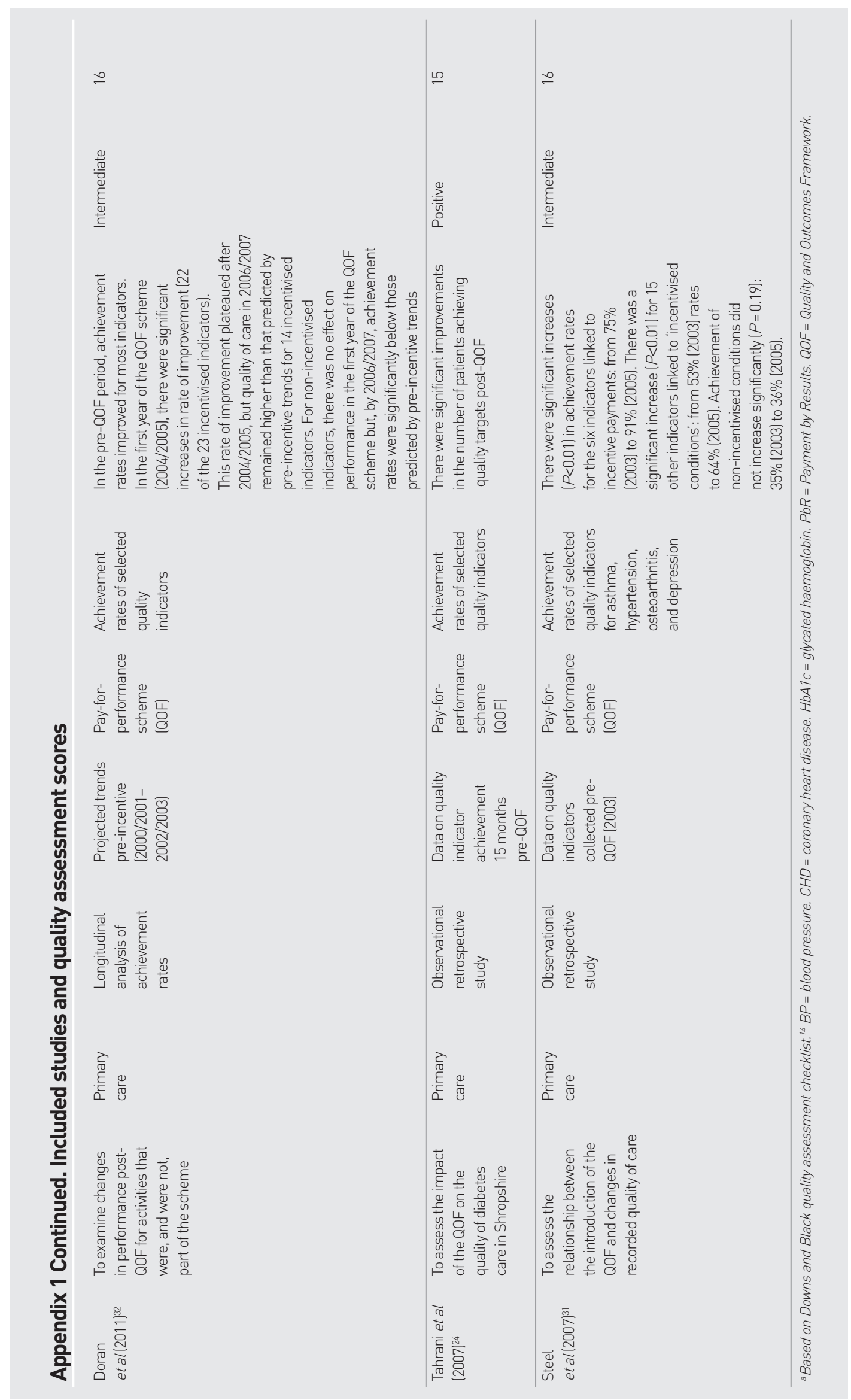

